УДК 658.6:65.014

DOI https://doi.org/10.32851/2708-0366/2021.6.10

Неіленко С.М.
кандидат технічних наук,
Київький національний університет культури і мистецтв
ORCID: https://orcid.org/0000-0002-7282-2682
Гуща Є.A.

аспірант,

Київський національний університет культури і мистецтв ORCID: https://orcid.org/0000-0002-3477-8617

Neilenko Sergii

Kyiv National University of Culture and Arts

Gushcha Evgeniya

Kyiv National University of Culture and Arts

\title{
ФОРМАЛІЗАЦІЯ ПОКАЗНИКІВ ВІДВІДУВАНОСТІ ДЛЯ ІВЕНТ-ЗАХОДІВ
}

\section{FORMALIZATION OF THE ATTENDANCE FOR EVENTS}

У статті розглянуто формалізацію показників відвідуваності для івент-заходів та виокремлено їхні характерні ознаки. Концеептуальні, теоретико-методологічні та методико-прикладні засади івент-заходів розглянуто вітчизняними та іноземними науковиями здебільшого фрагментарно, що актуалізує необхідність вирішення у цььому контексті широкого спектру завдань. Формалізовано визначення таких показників: середня тривалість перебування, середня кількість відвідувачів, відносна тривалість перебування, мультиплікатор відвідувачів, коефіиієнт змінюваності, пікове використання місткості, середнє використання місткості, частка використання місткості. Це дасть змогу суб'єктам івент-менеджменту та керівникам підприємств корегувати необхідне ресурсне забезпечення, процедури, індикатори, критерї тощуо для ефективнішої реалізації івент-заходів.

Ключові слова: виїзні заходи, захід, івент, івент-планування, кількість відвідувачів, менеджмент, подія, прогнозування, формалізація.

В статье рассмотрена формализащия показателей посещуаемости для ивент-мероприятий и выделены их характерные признаки. Концептуальные, теоретико-методологические и методико-прикладные основы ивент-мероприятий рассмотрены отечественными и иностранными учеными в основном фрагментарно, что актуализирует необходимость решения в этом контексте широкого спектра задач. Формализовано определение следуюших показателей: средняя продолжительность пребьвания, среднее количество посетителей, относительная длительность пребывания, мультипликатор посетителей, коэффициент сменяемости, пиковое использование вместимости, среднее использование вместимости, доля использования вместимости. Это позволит субъектам ивент-менеджмента и руководителям предприятий корректировать необходимое ресурсное обеспечение, процуедуры, индикаторы, критерии и т. д. для эффективной реализации ивент-мероприятий.

Ключевые слова: выездные мероприятия, мероприятие, ивент, ивент-планирование, количество посетителей, менеджмент, событие, прогнозирование, формализация.

The article considers the formalization of attendance ratio for events and underlines its characteristics. Conceptual, theoretical-methodological and methodological-applied principles of events are considered by scientists partially, which emphasizes the need to solve a wide range of problems in this context. From the standpoint of events in theory and practice its main parameters, stages and indicators are characterized. At the same time, a number of important tasks on this topic still remain unsolved. First of all, the formalization of event management indicators is considered partially, which complicates further research in the field of event management in enterprises. The purpose of the article is to formalize the attendance ratio in 
correlation with the duration of the event and to establish the importance of this quantitative outcome study for the financial success of the event project. Challenges of modernity adjust the new requirements for the service of various events. One of the criteria for a successful event is to determine attendance. The number of guests of one event is not an unknown quantity, nor is it a consequence of coincidence. Total quality event-management is characterized by the fact that the attendance can be predicted as accurately as possible, because the number of visitors is planned in terms of the effective event. In addition, the number of visitors can be optimized by managing it before the event and during it; deviations in the number of guests require a minor variation. The measurement of attendance ratio can be based on experience, the influence of internal and external factors, own actions and final records. However, a clear formalization of attendance ratio can improve the result. The definition of the following indications has been formalized: average length of stay, average number of visitors, relative length of stay, visitor multiplier, interchangeability ratio, peak space capacity, average space capacity, space capacity rate. This will allow event management entities and business leaders to adjust the necessary resources, procedures, indications and criteria for the effective implementation of event activities.

Key words: attendance, cycling of events, event, formalization, number of visitors, management, outdoor service, prediction, scheduling.

Постановка проблеми. Сучасність корегує нові вимоги до обслуговування різних заходів. Одним із критеріїв успішного проведення івент-заходу є визначення показників відвідуваності. Кількість гостей одного івент-заходу не $є$ невідомою величиною, так само як і не є наслідком збігу обставин. Якісний менеджмент заходу характеризується тим, що кількість відвідувачів може бути передбачена максимально точно, адже ця кількість гостей планується 3 погляду оптимального івент-заходу [1]. Окрім того, кількість відвідувачів можна оптимізувати, керуючи нею перед самим заходом і в процесі його проведення, відхилення в кількості гостей вимагає усвідомленої реакції. В основі оцінки показників відвідуваності можуть лежати досвід, вплив внутрішніх і зовнішніх чинників, власні дії і підсумкові записи. Однак чітка формалізація показників відвідуваності здатна поліпшити результат.

Аналіз останніх досліджень і публікацій. Організація івент-заходів та їх функціонування досліджувалися вітчизняними та іноземними науковцями. Найвідоміші праці належать таким вітчизняним дослідникам, як Л. Вовк, Г. Кунц, С. Попович, Н. Титова, В. Федоренко [14-16]. Проблеми функціонування та розвитку івент-менеджменту розглядали у численних наукових працях й іноземні вчені, такі як Д. Гетц, Р. Гріффін, Й. Лампел, А. Нігам, А. Олівер, М. Фолллетт [10-12].

Із позиції івентів у теорії та практиці звернено увагу на практичні аспекти, охарактеризовано його основні параметри, стадії та показники [2; 16, с. 254]. Водночас низка важливих завдань з указаної тематики досі залишається невирішеною. Перш за все формалізація показників івент-менеджменту розглянута лише частково, що ускладнює подальші наукові пошуки у сфері організації івент-заходів на підприємствах.

Формулювання цілей статті. Метою статті є формалізація показників відвідуваності залежно від тривалості івент-заходу та встановлення важливості вказаного показника для фінансового успіху івент-проєкту.

Виклад основного матеріалу. Під час планування і реалізації проєкту важливі як підготовчі роботи, так і підведення підсумків з аналізом результатів. Проведення івенту поділяють на етапи, кожний з яких відрізняється певними діями (табл. 1).

На фазах Ініціювання та Старту визначаються цілі, створюються програма і концепція івенту, визначається стратегія та проводиться планування підготовки та перебігу заходу [4; 9 , с. 840$]$.

Під час фаз Підготовки і Пуску розробляються плани (аналізуються попередні роботи, проводиться оцінка результатів); визначаються учасники; формується логістика; проводиться аналіз ризиків, структуризація, організація і реалізація проєкту івенту. 
Таблиця 1

Фази та етапи івент-заходу

\begin{tabular}{|c|c|}
\hline Фаза/етап & Дія \\
\hline Етап 0: Ідея & Формування ідеї щодо проведення івент-заходу \\
\hline Ініціювання & $\begin{array}{l}\text { Оформлення ідеї і визначення івент-заходу, підготовка проєкту } \\
\text { для осіб, що приймають рішення }\end{array}$ \\
\hline $\begin{array}{l}\text { Етап 1: } \\
\text { Так / Нi }\end{array}$ & $\begin{array}{l}\text { Ухвалення рішення про проведення івент-заходу. Оголошення про } \\
\text { івент-захід усередині організації, призначення виконавців } \\
\text { і керівників проєкту }\end{array}$ \\
\hline Старт & $\begin{array}{l}\text { Фаза планування: розподіл завдань, формування команд, планування } \\
\text { перебігу заходу, орієнтовне планування }\end{array}$ \\
\hline $\begin{array}{l}\text { Етап 2: } \\
\text { Вперед / Стоп }\end{array}$ & $\begin{array}{l}\text { Ухвалення рішення про підготовку (або про їі припинення), } \\
\text { складання кошторису, публічна заява про івент-захід } \\
\text { (починаючи із цього моменту відмова від проєкту тягне за собою } \\
\text { фінансові і моральні збитки) }\end{array}$ \\
\hline Підготовка & $\begin{array}{l}\text { Остаточне планування: підготовка і організація івент-заходу; } \\
\text { завдання і доручення, запрошення гостей }\end{array}$ \\
\hline $\begin{array}{l}\text { Етап 3: } \\
\text { Крапка неповернення }\end{array}$ & $\begin{array}{l}\text { Початок фази пуску: активізація і висування вимог до планування; } \\
\text { відтепер виникають витрати великого обсягу }\end{array}$ \\
\hline Пуск & $\begin{array}{l}\text { Початок івенту, активна діяльність з облаштування місця } \\
\text { проведення, монтажу споруд і обладнання, постачання, забезпечення } \\
\text { прибуття }\end{array}$ \\
\hline $\begin{array}{l}\text { Етап 4: } \\
\text { Відчинені двері }\end{array}$ & Event стартує; офіційне відкриття, привітання (можливо пізніше) \\
\hline Дія & Час контакту приймаючої сторони і запрошених гостей \\
\hline $\begin{array}{l}\text { Етап 5: } \\
\text { Закінчення }\end{array}$ & Закінчення івент-заходу, офіційне закриття, прощання \\
\hline Наслідки & $\begin{array}{l}\text { Завершення івент-заходу: демонтаж споруд та обладнання, } \\
\text { повернення поставок, організація від'їзду }\end{array}$ \\
\hline $\begin{array}{l}\text { Етап 6: } \\
\text { Завершення }\end{array}$ & Припинення дій і закінчення розрахунків \\
\hline Підведення підсумків & Заключні організаційні роботи. Обробка даних, фінансовий звіт \\
\hline $\begin{array}{l}\text { Етап 7: } \\
\text { Закінчення проєкту }\end{array}$ & Проєкт закрито \\
\hline
\end{tabular}

Фаза Дія включає у себе привітання учасників, обслуговування та поточний контроль над якістю проведення івенту та кількістю відвідувачів [5, с. 183; 14, с. 70].

Фаза Наслідки і Підведення підсумків передбачає демонтаж споруд та обладнання; документування процесу; зворотний зв'язок, оцінка відповідей, обробка даних, внесення поправок; звільнення від обов'язків залучених співробітників; прийняття рішень про майбутні заходи.

За тривалого або подовженого заходу важливо визначити критерії оцінювання кількості відвідувачів, за якими можуть бути оцінені певні складові частини заходу, дні або місця їх проведення. Завдяки цьому виділяються основні «центри тяжіння» (зони з високою кількістю відвідувачів) і «вузькі місця» (зони з високим ступенем використання місткості).

Івент включається в організаційну структуру підприємства різними способами. По-перше, формуванням власного структурного підрозділу, діючого на постій- 
ній основі. Це має сенс тоді, коли заходи готуються і проводяться регулярно, що забезпечує гарантію завантаження даного підрозділу (а також у разі необхідності залучення його до вирішення інших задач) [6, с. 73]. По-друге, відокремленою від організації тимчасовою структурою, що актуально насамперед під час проведення великих заходів і в окремих випадках може стати основою для виникнення самостійної фірми, що займається реалізацією івенту [7]. По-трете, матричним способом, коли з різних задіяних підрозділів набираються співробітники в івент-команду $[8$, c. 318$]$.

Основними показниками, які характеризують івент-захід і його успіх, є середня відвідуваність, коефіцієнт змінюваності і рівномірність відвідуваності.

Коефіцієнт змінюваності (W) являє собою частку, отриману шляхом ділення загальної показників відвідуваності (G) на пікову відвідуваність (S). Формулу можна представити як $\mathrm{W}=\mathrm{G} / \mathrm{S}$. При цьому значення $\mathrm{W}=1$ (мінімально можливе) показує, що на даний момент присутні всі гості.

Передумови для високого значення $\mathrm{W}$, як правило, такі:

- регулярна змінюваність: термін перебування D менший, аніж тривалість заходу V. Коефіцієнт змінюваності $\mathrm{W}=\mathrm{V} / \mathrm{D}$ за рівномірної відвідуваності (наприклад, виставки, де тривалість огляду становить кілька годин);

- активне зростання показників відвідуваності на початку й їі зменшення до кінця заходу без накладок у часі (наприклад, на дні відкритих дверей, де не всі гості присутні одночасно);

- змінюють один одного відвідувачі багатоденних заходів (наприклад, кінець святкового тижня з п’ятничною поп-програмою, суботнім вечором фолк-музики і концертом у неділю) або заходів тривалістю в один день (участь у денній програмі, вечірній вихід при параді).

За значення $\mathrm{W}>1$ різні гості можуть бути присутніми в різний час (наприклад, хтось до обіду, хтось після - під час спільного обіду).

Під час довготривалих заходів слід розділяти відвідувачів, які мають необмежену кількість входу, і тих, хто входить одноразово. Кількість останніх визначається за фіксованим числом входів, перше - за кількістю проданих квитків або за списками.

Графік (рис. 1) показує два можливих варіанти як за однієї заданої кількості гостей за годину може варіюватися їх загальне і пікове число.

Високий коефіцієнт змінюваності означає, що:

- не всі гості беруть участь у всіх складниках івент-заходу (особливо це стосується відкриття та закриття);

- у всіх відвідувачів складається своє уявлення про подію;

- місткість виїзного заходу становить лише частину $(1 / \mathrm{W})$ від загальної кількості гостей.

Під час планування івент-заходів потрібно диференційовано визначати різні показники відвідуваності, охоплювати їх і управляти ними. Ще на стадії виникнення ідеї за високого коефіцієнту змінюваності потрібно взяти до уваги різницю між сукупним івент-заходом із погляду організаторів й івент-заходом в уявленні гостей [12, с. 1158].

Середня кількість відвідувачів (M) - це частка від ділення кількості людино-годин (B) на загальну тривалість заходу (V), тобто $\mathrm{M}=\mathrm{B} / \mathrm{V}$. Показник середньої відвідуваності відображає лише те, наскільки використовується місткість залу К. За повного використання $\mathrm{M}=\mathrm{K}$.

Середня кількість відвідувачів (M) менша, ніж пікова кількість відвідувачів (S), а остання, своєю чергою, не перевищує місткість (К), тобто $\mathrm{M} \leq \mathrm{S} \leq \mathrm{K}$. Ступінь використання $\mathrm{m}=\mathrm{M} / \mathrm{K} \leq 1$. На коефіцієнт частки використання $\mathrm{q}=\mathrm{G} / \mathrm{K}$ впливає велика кількість чинників, тому його значення може бути як більшим (за високої змінюваності відвідувачів), так і меншим (у разі неповного використання місткості). Значення 
$\mathrm{q}=1$ може виникати в тому разі, коли захід уміщує 25\% відвідувачів, але окремі гості присутні постійно лише чверть часу.

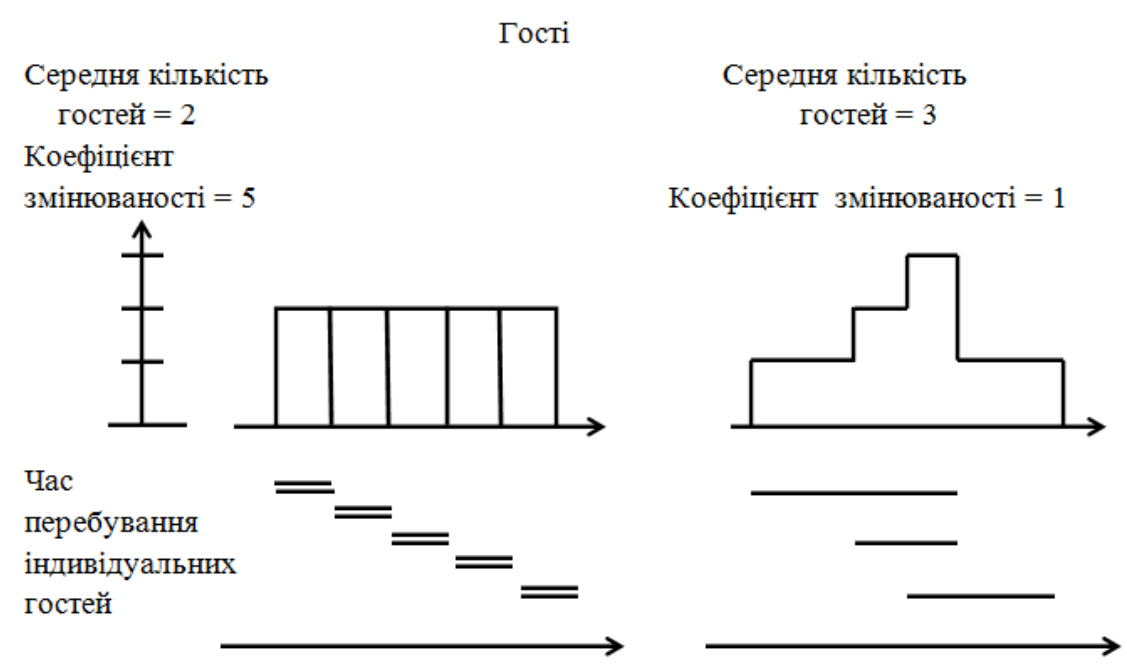

Рис. 1. Коефіиієнт змінюваності відвідуваності івент-заходів

Кількість гостей одного заходу не $є$ невідомою величиною, так само як і не є наслідком збігу обставин. Якісний менеджмент заходу характеризується тим, що [11, с. 839]:

- кількість відвідувачів може бути передбачена максимально точно;

- кількість гостей планується з погляду оптимального івент-заходу;

- кількість відвідувачів можна оптимізувати, керуючи нею перед заходом і в процесі його проведення;

- відхилення в кількості гостей вимагають усвідомленої реакції.

В основі оцінки показників відвідуваності можуть лежати досвід, вплив внутрішніх і зовнішніх чинників, власні дії і підсумкові записи. У багатьох випадках отримання незалежної оцінки здатне поліпшити результат.

Правильне визначення кількості гостей важливе у зв'язку з тим, що:

- порожні зали настільки ж критичні для сприйняття події, як і довгі черги;

- для фінансового успіху необхідна велика кількість учасників; лемами.

- перевищення допустимої місткості загрожує різного роду ризиками і проб-

Оцінка показників відвідуваності, спостереження за нею та управління вкрай важливі для успіху заходу. Тут можливі такі заходи, як [13, с. 110; 16, с. 254]:

- планування події з урахуванням місткості і коефіцієнта змінюваності, потенційної зацікавленості та цілей івент-заходу;

- управління за допомогою комунікації, укладення контрактів (наприклад, стосовно ціноутворення та інших умов) і спрямування потоку відвідувачів у певне русло (у певній послідовності);

- реагування на відхилення шляхом спроб регулювання чи адаптації заходу:

- просторове або часове розширення чи скорочення заходу;

- додаткові заходи іншого характеру, наприклад організація розваг для гостей що стоять у черзі.

Відповідно до вищевикладеного, формалізовано кореляцію між кількістю відвідувачів та тривалістю івент-заходу (табл. 2, 3). 
Таблиця 2

\section{Параметри формалізації показників відвідуваності} залежно від тривалості заходу

\begin{tabular}{|l|l|l|}
\hline \multicolumn{1}{|c|}{ Позначення } & \multicolumn{1}{|c|}{ Формули і умови } & \multicolumn{1}{c|}{ Значення } \\
\hline V: тривалість заходу & Дія & $\begin{array}{l}\text { Орендна плата, витрати на } \\
\text { одну особу, програма }\end{array}$ \\
\hline K: місткість & $\begin{array}{l}\text { Максимальна кількість } \\
\text { відвідувачів }\end{array}$ & $\begin{array}{l}\text { Орендна плата, страхування, } \\
\text { безпека, інфраструктура }\end{array}$ \\
\hline $\begin{array}{l}\text { G: загальна кількість } \\
\text { відвідувачів }\end{array}$ & $\begin{array}{l}\text { Кількість усіх гостей, які } \\
\text { зайшли }\end{array}$ & $\begin{array}{l}\text { Вхідні квитки, в'їзд } \\
\text { транспортних засобів }\end{array}$ \\
\hline В: кількість людино-годин & $\begin{array}{l}\text { Сума часу присутності всіх } \\
\text { відвідувачів }\end{array}$ & Присутність, споживання \\
\hline S: пікова кількість відвідувачів & М $\leq \mathrm{S} \leq \mathrm{K}$ & $\begin{array}{l}\text { Використання місткості, } \\
\text { безпека, послуги }\end{array}$ \\
\hline
\end{tabular}

Формалізація показників івент-заходів та їх характеристика

Таблиця 3

\begin{tabular}{|c|c|c|}
\hline Позначення показника & $\begin{array}{l}\text { Формалізація } \\
\text { показника }\end{array}$ & Характеристика показника \\
\hline $\begin{array}{l}\text { tm: Середня тривалість } \\
\text { перебування }\end{array}$ & $\operatorname{tm}=\mathrm{B} / \mathrm{G} \leq \mathrm{V}$ & $\begin{array}{l}\text { Характер івент-заходу з погляду } \\
\text { відвідувачів }\end{array}$ \\
\hline $\begin{array}{l}\text { М: Середня кількість } \\
\text { відвідувачів }\end{array}$ & $\mathrm{M}=\mathrm{B} / \mathrm{V}=\mathrm{Gxtm} / \mathrm{V}$ & Використання місткості \\
\hline $\begin{array}{l}\text { r: Відносна тривалість } \\
\text { перебування }\end{array}$ & $\mathrm{r}=\mathrm{tm} / \mathrm{V}=\mathrm{M} / \mathrm{G}$ & $\begin{array}{l}\text { Співвідношення точки зору } \\
\text { відвідувачів і івент-заходу в цілому }\end{array}$ \\
\hline Q: Мультиплікатор відвідувачів & $\mathrm{Q}=\mathrm{G} / \mathrm{M}=1 / \mathrm{r}$ & $\begin{array}{l}\text { Досягнення цілей окремих частин } \\
\text { заходу }\end{array}$ \\
\hline W: Коефіцієнт змінюваності & $\mathrm{W}=\mathrm{G} / \mathrm{S}$ & \\
\hline $\begin{array}{l}\text { s: Пікове використання } \\
\text { місткості }\end{array}$ & $\mathrm{s}=\mathrm{S} / \mathrm{K} \leq 1$ & $\begin{array}{l}\text { Успіх, використання всіх } \\
\text { можливостей }\end{array}$ \\
\hline $\begin{array}{l}\text { m: Середнє використання } \\
\text { місткості }\end{array}$ & $\mathrm{m}=\mathrm{M} / \mathrm{K} \leq \mathrm{S}$ & \\
\hline $\begin{array}{l}\text { q: Частка використання } \\
\text { місткості }\end{array}$ & $\mathrm{q}=\mathrm{G} / \mathrm{K}=\mathrm{Qxm}=\mathrm{m} / \mathrm{r}$ & $\begin{array}{l}\text { Кількість відвідувачів по } \\
\text { відношенню до місткості }\end{array}$ \\
\hline
\end{tabular}

Висновки. Фрмалізовано критерії для прогнозування показників відвідуваності івент-заходу. Правильне визначення кількості гостей важливе у зв'язку з тим, що порожні зали настільки ж критичні для сприйняття події, як і довгі черги. Для фінансового успіху необхідна велика кількість учасників, але перевищення допустимої місткості загрожує різного роду ризиками і проблемами.

\section{Список використаних джерел:}

1. 4 Goals to Set for Your Event Planning Business This Year, 2017. URL: https://www.qceventplanning.com/blog/2017/12/4-goals-set-event-planning-business-year/ (дата звернення: 03.02.2021).

2. 7 Characteristics of a Successful Event. Attendee Events, 2016. URL: https://attendee.events/ 7-characteristics- successful-event/ (дата звернення: 07.02.2021).

3. The 10 Event Management Skills Event Managers Need. Eventbrite. URL: https://www.eventbrite.co.uk/blog/qualities-successful-event-managers (дата звернення: 12.02.2021). 
4. The Different Types of Events: A Comprehensive List. Eventbrite. URL: https://www.eventbrite.co.uk/blog/the- different-types-of-events-ds00/ (дата звернення: 19.02.2021).

5. Федоренко В.Г. Менеджмент : підручник. Київ : Алерта, 2015. 492 с.

6. Follett M.P. Dynamic Administration: The Collected Papers of Mary Parker Follett. Eastford : Martino Fine Books. 2014.

7. Eventbrite. The 10 Event Management Skills Event Managers Need. 2019. URL: https://www.eventbrite.co.uk/blog/qualities-successful-event-managersds (дата звернення: 26.02.2021).

8. Кузьмін О., Мельник О. Теоретичні та прикладні засади менеджменту : навчальний посібник. Львів : Львівська політехніка ; Інтелект-Захід, 2007. 384 с.

9. Lampel J., Shamsie J., Shapira Z. Experiencing the improbable: Rare events and organizational learning. Organization Science. 2009. № 20. P. 835-845.

10. Griffin L.J. Temporality, events and explanation in historical sociology: An intro-duction. Sociological Methods \& Research. 1992. № 20. P. 403-427.

11. Nigam A., Ocasio W. Event attention, environmental sense making, and change in institutional logics: An inductive analysis of the effects of public attention to Clinton's Health Care Reform Initiative. Organization Science. 2010. № 21. P. 823-841.

12. Oliver A.L., Montgomery K. Using field-configuring events for sense-making: A cognitive network approach. Journal of Management Studies. 2008. № 45. P. 1147-1167.

13. Getz D., Andersson T. Editorial to the special issue on festival management. Scandinavian Journal of Hospitality and Tourism. 2009. № 9. P. 109-111.

14. Титова Н. Діловий туризм в Україні: основні проблеми розвитку та шляхи їхнього вирішення. Економіка і менеджсмент культури. 2013. № 1. С. 67-74.

15. Вовк Л. Перспективи розвитку ділового туризму в Україні. Сучасні проблеми і перспективи економічної динаміки : матеріали IV Всеукраїнської науково-практичної конференції. Умань : Візаві, 2017. С. 270-271.

16. Попович С. Індустрія міжнародного туризму та його розвиток за сучасних умов. Вісник Львівського університету. Серія «Міжнародні відносини». 2008. № 24. С. 252-255.

\section{References:}

1. 4 Goals to Set for Your Event Planning Business This Year, 2017. Available at: https://www.qceventplanning.com/blog/2017/12/4-goals-set-event-planning-business-year/ (accessed 03 February 2021).

2. 7 Characteristics of a Successful Event. Attendee Events, 2016. Available at: https://attendee.events/7- characteristics-successful-event/ (accessed 7 February 2021).

3. The 10 Event Management Skills Event Managers Need. Eventbrite. Available at: https://www.eventbrite.co.uk/blog/qualities-successful-event-managers-ds00/ (accessed 12 February 2021).

4. The Different Types of Events: A Comprehensive List. Eventbrite. Available at: https://www.eventbrite.co.uk/blog/the-different-types-of-events-ds00/ (accessed 19 February 2021).

5. Fedorenko V. G. (2015) Management [Management]. Kyiv: Alerta. (in Ukrainian)

6. Follett M. (2014) Dynamic Administration: The Collected Papers of Mary Parker Follett. Eastford : Martino Fine Books.

7. Eventbrite (2019) The 10 Event Management Skills Event Managers Need. Available at: https://www.eventbrite.co.uk/blog/qualities-successful-eventmanagers (accessed 26 February 2021).

8. Kuzmin O., Melnyk O. (2007) Teoretychni ta prykladni zasady menedzhmentu [Theoretical and applied principles of management]. Lviv: Lviv Polytechnic National University ; "IntelektZahid". (in Ukrainian)

9. Lampel J., Shamsie J., Shapira Z. (2009) Experiencing the improbable: Rare events and organizational learning. Organization Science, no. 20, pp. 835-845.

10. Griffin L.J. (1992): Temporality, events and explanation in historical sociology: An intro-duction. Sociological Methods \& Research, no. 20, pp. 403-427.

11. Nigam A., Ocasio W. (2010) Event attention, environmental sensemaking, and change in institutional logics: An inductive analysis of the effects of public attention to Clinton's Health Care Reform Initiative. Organization Science, no. 21, pp. 823-841.

12. Oliver A.L., Montgomery K. (2008):Using fieldconfiguring events for sense-making: A cognitive network approach. Journal of Management Studies, no. 45, pp. 1147-1167. 
13. Getz D., Andersson T. (2009) Editorial to the special issue on festival management. Scandinavian Journal of Hospitality and Tourism, no. 9, pp. 109-111.

14. Tytova N. (2013) Dilovyi turyzm v Ukraini: osnovni problemy rozvytku ta shliakhy yikhnoho vyrishennia [Business tourism in Ukraine: main problems of development and ways of their solution]. Economics and management of the culture, no. 1, pp. 67-74.

15. Vovk L. (2017) Perspektyvy rozvytku dilovoho turyzmu v Ukraini [Business tourism development prospects in Ukraine]. Uman: VPC "Vizavi" (Materialy IV Vseukrainskoi naukovo-praktychnoi konferentsii "Suchasni problemy i perspektyvy ekonomichnoi dynamiky"), pp. 270-271.

16. Popovych S. (2008) Industriia mizhnarodnoho turyzmu ta yoho rozvytok za suchasnykh umov [The international tourism industry and its development in modern conditions]. Visnyk Lvivskoho universytetu. Seriia mizhnarodni vidnosyny, vol. 24, pp. 252-255. 